\title{
Research on Non-verbal Graphic Symbol Communication of Cross-Border e-Commerce
}

\author{
Yuhui Feng ${ }^{*}$ and Meiyun Hua \\ Business School, Yunnan University of Finance and Economics, China \\ fengyu9@hotmail.com \\ huameiyun@126.com
}

\begin{abstract}
Promoting e-commerce in Southeast Asia and South Asia has language barriers. There are many languages in the region that have a very limited number of speakers. And not many ordinary people use English for their communication purposes. Online translation software does not include such languages like Burmese and Laos. Therefore, it is necessary to explore alternative methods for instant network communication. This paper explores the use of non-verbal graphic symbols for instant communication in the cross-border ecommerce context by borrowing theories and methods from linguistics, psychology, semiotics, graphic design and computer science to enrich this approach.

This paper designed and implemented three experiments: (1) the cognitive effect of non-verbal symbols and network graphical symbols experiment, (2) the cognitive efficiency experiment of non-verbal graphic symbols and a global language such as English and (3) a simulated communication experiment using graphical symbols. Experimental results show that designed non-verbal graphical symbols are recognizable can be used as media for simple communication purposes in e-commerce after some training.

This study has the potential to contribute to cross-border e-commerce by less educated groups of small regional language speakers. It may also contribute to special purpose communications as well as providing an embodiment of the need to use graphic expressions.
\end{abstract}

Keywords: Non-verbal graphic communication symbols, online instant communication, cross-border e-commerce, e-Business.

\section{Introduction}

Current cross-border e-commerce websites provide three language solutions: (1) web pages are in different language; (2) translation software is available for instant web page translation;(3) human interpreters are used to offer synchronous or asynchronous translation services. The first method is used for news release in static web pages but not very applicable to interactive e-commerce activities. The second method has two main problems. First, software translation has limited accuracy of about $70 \%$. Second, most of the translation software does not provide translation for languages with small

\footnotetext{
* Corresponding author.
} 
number of speakers such as Khmer, Laotian and Burmese and other ethnic minority languages. The third method is restrained by the high cost of human translators, the delay in response and the difficulty to maintain long-term high quality services. In addition to that, the Europe approach of using English as the communicative media does not apply in other cultures or regions.

Given that e-commerce operates in a virtual environment, users' level of education is unpredictable; the limitation of English as the communicative media for e-commerce and translation software does not support small languages, exploring alternative methods of communication has practical significance.

So, our research question is: Can we conduct simple and preliminary communications using non-verbal graphic symbols in cross-border e-commerce?

If it is any hint, the application of graphical symbols in Internet communications may have practical implications.

On September 19, 1982 at 11:44 am, Carnegie Mellon university professor Scott Fahlman set the precedent in the BBS of the Internet by typing a string ": -)", emoticons to express feelings. The emoticons spread quickly in the BBS, and developed. Later the Martian symbols appeared in online social networks to convey specific information. Examples are 'Orz' (bowing down in hieroglyphic method, like a man three letters fell to his knees on the ground) and '@@' (feeling dizzy). Along with the development of Web instant communications technology, in the instant communication network applications such as MSN, QQ and WeChat, people developed graphic emoticons to replace the character emoticons that are not easy to remember. After that animated graphic symbols were adopted thus adding business significance to these symbols (Fig. 1). Feng Cheng (2005) found that "in the SCMC (based synchronous computer - mediated communication) context, people used the non-verbal symbols for entertainment mentality and emotional needs hence giving these non-verbal symbols the inherent function of communicating entertainment and expression."[1]. Since then, graphic symbols in addition to expressing emotions have gained added meanings.
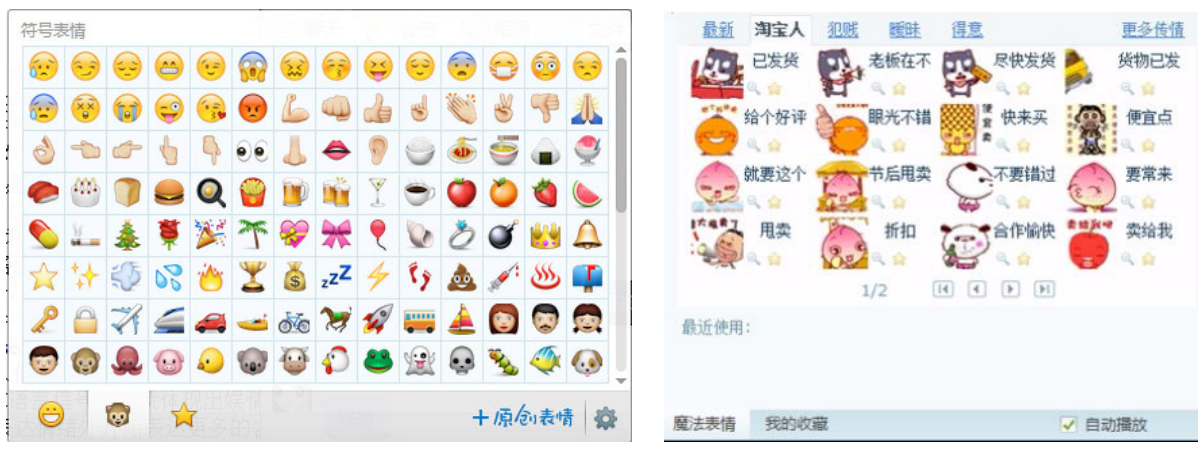

Fig. 1. Emoticons graphic symbols, animated graphic symbols and business graphic symbols 
In addition to expressing emotions, graphic symbols have gained new uses. With the development of social media, people began to upload large numbers of pictures in forums such as Baidu Post Bar and via communication software to express richer meanings and meanings that are hard to convey in language. This then led to the development of a visual language.

There are also attempted complete narratives by using graphical symbols. For example, a painter named Xu Bing (2012) depicted the life of a white collar worker in a day using graphic symbols in his book "To book: from point to point"[2]. Figure 2 is a paragraph from the book demonstrating Bing Xu's words-graphic symbol translation system. This is an experiment using graphic symbols to convey meaning.

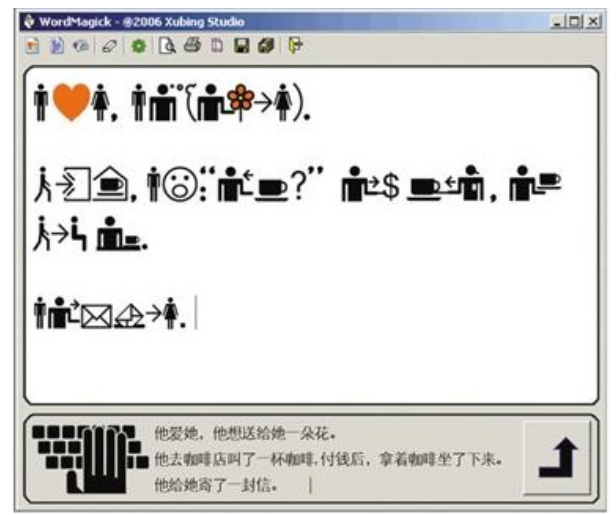

Fig. 2. Bing Xu's narrative in graphic symbols

\section{Conceptual Background}

No research paper has been documented studying the use of non-verbal graphic symbols in business, especially in the context of the multi-lingual environment in Southeast Asia. But that does not exclude the following relevant studies.

Nonverbal graphic symbols communication has become a way for people to communicate. Cheng (2005) argues that "computer-mediated communication (CMC) has become an important means of human communication." "In online socializing computer users have developed a set of nonverbal cues popular among netizens to compensate for the lack of nonverbal cues in CMC context. Non-verbal communication in SCMS is classified into three types: graphic accents, electronic paralanguage and emoting. Graphic accents fall into two kinds: emotions and pictures. Emotions usually include keyboard symbols and ASCII codes to indicate users' mood or states of mind. Pictures are content-rich picture icons or animated pictures originated from the Internet. Electronic paralanguage is a set of innovative nonverbal cues created by communicators mainly through the strategic use of typography for emphasis or effect enhancement. Action description is also categorized as a method of nonverbal communication. Action description (Emotion?) refers to the narrative descriptions of the user's current emotional or physical state in the third person"[1]. 
Studies show that nonverbal symbols can be directly felt, do not require a lot of thinking and analysis. It is also found that clear and systematic nonverbal symbols can improve cognitive efficiency and reliability. The most representative study was conducted by Standing in 1973 [3]. In this study, 2500 slides were shown to the subjects in 10 seconds. Then the slides were shown again in pairs for the subjects to identify. The results showed that even if the new slides were shown only for 1 second, or when the original slides were mirrored, $85 \%$ - $95 \%$ of the slides were correctly identified.

King (1971) did an experiment comparing the cognitive difference between nonverbal graphical symbols and text. His founding was that people were able to match nonverbal graphic symbols more quickly than the text. Also, $65 \%$ of the subjects believed that it was easier to match the nonverbal graphic symbols than the text [4]. Based on another study regarding the correct recognition of texts and symbols, Walker (1965) came to a similar conclusion that nonverbal graphic symbols have a higher recognition rate than texts [5]. Thus, Horton (1994) agreed that non-verbal graphic symbols were visually easier to recognize than texts and easier to remember too. Nonverbal graphic symbols have both verbal memory and visual memory, and texts have only verbal memory. Therefore, the human visual perception system has powerful cognitive and identifying ability for symbols. For well-designed graphical nonverbal symbols, people's cognition is even more rapid and accurate [6].

As can be seen from the above studies in other fields, nonverbal graphic symbols have better cognitive recognition and higher cognitive efficiency. Thus we propose the following hypotheses.

H1: In the context of e-commerce, people can effectively recognize graphic symbols designed by following the rules of cognitive psychology and linguistics.

$\mathrm{H} 2$ : The cognitive effect of graphic symbols is acceptable relative to that of the verbal signs.

H3: Preliminary communication in graphic symbols is possible after some training in them.

In order to verify the above hypothesis, we have designed three experiments.

E1. The cognitive effect experiment of non-verbal symbols and network graphic symbols, designed to assess whether the designed nonverbal graphic symbol system is reliable as a system and whether it is easy to recognize or easy to use.

E2. The cognitive efficiency experiment of non-verbal symbols and such global language symbols as English. The experiment was designed to evaluate the cognitive effect of designed graphic symbols by means of a cognitive test of both designed nonverbal graphic symbols and linguistic symbols.

E3. A simulated communication experiment using nonverbal graphic symbols. The purpose of this experiment was to test whether two-way communication using nonverbal graphic symbols in the e-commerce context can be achieved after both parties of the communication were properly trained. 


\section{Methodology}

\subsection{Experimental Material Preparation}

We prepared two sets of non-verbal material and a set of graphical symbols for English learning material, called material 1, material 2 and material 3.

Material 1: picture collected from Internet, show as Table 1. These graphical symbols have the same style, more commonly used. To avoid the influence of the color, all graphic symbols are processed into black and white figure.

Material 2: icons designed the nonverbal graphic symbols as shown in table 2. It is designed based on some knowledge of cognitive psychology, cognitive linguistics and graphic design.

Material 3: learning materials adopted 'New Cambridge Business English (primary)' in business consulting part of school textbooks.

Table 1. Sample picture part of material 1 Table 2. Sample graphic symbol part of material 2
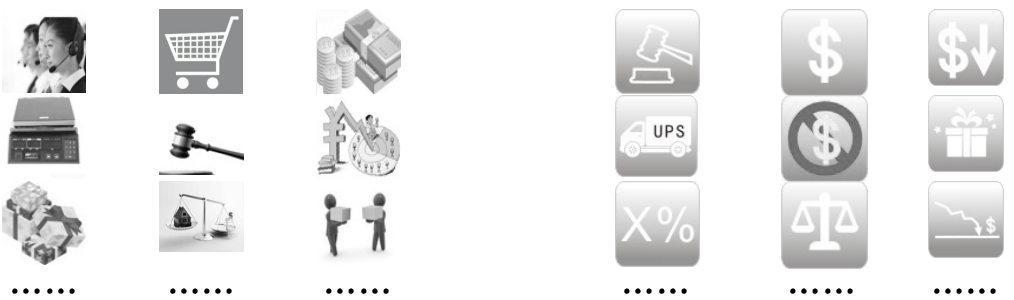

\subsection{Participants}

In this study, subjects with diverse gender, age, education, respectively, from Thailand, Laos, Vietnam, China, undergraduate, graduate students and exhibitors ASEAN Expo, A total of 94 people. Intelligence and vision of all the subjects are normal.

\subsection{Experimental Design}

\section{Experiment 1}

For 94 subjects, due to the Likert scale questionnaire survey results has independent of features with personnel level, experience, and knowledge and so on, and therefore don't need to consider when designing the experimental program the subject components affect experimental results generated.

Using questionnaire survey, the symbol design results are subjective evaluation. Experiment principle using Likert (1932) scale of psychology experiment method. It belongs to the one of the rating aggregation type scale that most commonly used. The scale consists of a set of statements consisting. Each group statement has five kinds of answers, such as "very", "less", "general", "more" and "very". Subjects are asked to express the views for each group of statements and icon related to the experiment, and 
$t$ and clearly the extent of its holdings attitudes [7]. In making Likert scale questionnaire, this paper adopted Gittins (1986) put forward to evaluate symbols of the six factors, namely, can associate, can be recognized, meaning clear, concise design, attractive and symbolic [8]. The researchers randomly selected 10 symbols from material 1 and 2, and made the questionnaire. Each symbol is set up six factors scale, each scale are set five decision values. Table 3 is an example of the questionnaire.

Table 3. The sample of questionnaire

\begin{tabular}{|c|c|c|c|c|c|c|c|}
\hline & & $\begin{array}{l}\text { can } \\
\text { associate }\end{array}$ & $\begin{array}{l}\text { can be } \\
\text { recognized }\end{array}$ & $\begin{array}{l}\text { meaning } \\
\text { clear }\end{array}$ & $\begin{array}{l}\text { concise } \\
\text { design }\end{array}$ & attractive & symbolic \\
\hline $1-1$ & \multirow[b]{2}{*}{ money } & & & & & & \\
\hline $2-1$ & & & & & & & \\
\hline
\end{tabular}

\section{Experiment 2}

24 invited participants were not with graphic symbols or English learning experience. Therefore, under the same conditions that reflects characteristics of two language systems in learning and cognitive efficiency. In order to make the experiment with a more intuitive contrast, this test used two different language systems, material 2 and material 3. Depending on the material, we grouped subjects. On the use of material 2 symbol system team labeled A, using English language system team labeled B. Where group A and group B, each of 12 people.

Experimental 2 consists of two processes: learning process and testing process. Learning process: By reading training to learn the designed Non-verbal graphic symbols and common language (English), then let the subjects get some understanding about Non-verbal graphic symbols and common language. Based on the learning, through identification tests set out by the experiment, we can analysis level of these subjects reorganization between Non-verbal graphic symbols and international common language, and take the result as judgment to evaluate these symbols. Training and testing process should be alternately, as learning, testing, learning... At the same time, each learning time specified in Table 4.This time lamination is determined by some subjects' experimentation (Note: They don't participate in formal experimental test).

Table 4. Cumulative learning time of six experiments

\begin{tabular}{ccccccc}
\hline Cycle experiment & $1 \mathrm{st}$ & 2nd & 3 rd & 4 th & 5 th & 6 th \\
\hline Cumulative time & $3 \mathrm{~min}$ & $3 \mathrm{~min}$ & $6 \mathrm{~min}$ & $6 \mathrm{~min}$ & $9 \mathrm{~min}$ & $9 \mathrm{~min}$ \\
\hline
\end{tabular}

This experiment adopts filling in the blanks type rules for identification test. I give some symbols to subjects, that subjects can describe and explain graphic symbols on the basis of learning symbol's system. This test can reflect whether the graphic symbol system is easy to understand recognize, remember and use. Developed a total of 
12 sets of experimental test papers, numbered A-1, A-2, ..., A-6 (randomly selected from the material 2) and B-1, B-2, ..., B-6 (random selected from material 3). Each set of test papers total of ten symbols, need the subjects to answer symbolic representation of meaning after learning. Experiment 2 test papers are shown in Table 5 and 6.

Table 5. Experiment 2 Test paper (Part)

\begin{tabular}{ccc}
\hline $\begin{array}{c}\text { Sequence Num- } \\
\text { ber }\end{array}$ & Graphic symbol & $\begin{array}{c}\text { Please give its characterization based on the } \\
\text { significance of graphic symbols }\end{array}$ \\
\hline 1 & & \\
2 & & \\
$\ldots$ & $\ldots \ldots$ & $\ldots \ldots$ \\
\hline
\end{tabular}

Table 6. Test paper (Part)

\begin{tabular}{ccc}
\hline $\begin{array}{c}\text { Sequence Num- } \\
\text { ber }\end{array}$ & English word & $\begin{array}{c}\text { Please give its characterization based on the } \\
\text { English word }\end{array}$ \\
\hline 1 & Money & \\
2 & Weight & $\ldots \ldots$ \\
$\ldots$ & $\ldots \ldots$ & $\ldots \ldots$ \\
\hline
\end{tabular}

From cognitive experimental variables analysis, Experiment 2 mainly affected by "the length of training time" the independent variable. Therefore, in this experimental program designed to deal with the independent variables investigated. Working staff were asked to try to make rigorous, reducing experimental noise accidental errors.

\section{Experiment 3}

Experiment 3 is based on Experiment 2. The first group of members in experiment 2 received training in non-verbal graphic symbols designed for this study so that they had some basic understanding of the graphs thus satisfying the requirement for research participants. The experiment verify whether can use nonverbal symbols to twoway communication on both sides under the e-commerce context. This experiment uses the symbols system of material 2 and English language of material 3. When developed, we retain a number of symbols that are not used in experiment 2 to be used in experiment 3.

Members were in Experiment 2. Then these participants were divided into groups $\mathrm{X}$ and $\mathrm{Y}$ with group $\mathrm{X}$ organizing the symbols into graphs using provided conceptual ideas and group $\mathrm{Y}$ attempting to translate these organized graphs. The questionnaire is shown in Table 7.

\subsection{Procedures}

\section{Experiment 1}

Grant questionnaire to subjects, and clarify the relevant matters needing attention when answer the questionnaire, ensure that all participants personnel seriously think 
and evaluate symbols. After subjects answer the questionnaire, researchers receive questionnaire.

Table 7. Sample volume

Experiment 3 : Communication process simulation I (first cycle of group $\mathbf{X}$ )

1. Basic information of group X members (Omission)

2. Answer team Y symbol combinations

\begin{tabular}{|l|l}
\hline \multicolumn{1}{|c|}{ Sequence Number } & \multicolumn{1}{c}{ Semantic } \\
\hline 1 & The price can't be any cheap. \\
\hline$\ldots \ldots$ & $\ldots \ldots$ \\
\hline 5 & Free shipping \\
\hline
\end{tabular}

C $\underline{\text { utting }}$ line

Experiment 3 : Communication process simulation I (first cycle of group Y)

1. Basic information of group Y members (Omission)

2. Answer team $X$ symbol combinations

\begin{tabular}{|l|l|l}
\hline $\begin{array}{l}\text { Sequence } \\
\text { Number }\end{array}$ & $\begin{array}{l}\text { The result of graphic symbol made up } \\
\text { by group X }\end{array}$ & $\begin{array}{l}\text { The result of graphic symbol Answere } \\
\text { by group Y }\end{array}$ \\
\hline 1 & & \\
\hline$\ldots \ldots$ & & $\ldots \ldots$ \\
\hline 5 & & \\
\hline
\end{tabular}

\section{Experiment 2}

Experiment 2 were arrangement of six "learning - recognition" cycle. For each learning cycle are made of different test papers. Each piece of paper is randomly drawn from the use of two language systems. The purpose of doing so is to investigate the extent of the subjects to understand and grasp the whole symbols system, which reflects on the cognitive performance in two sets of language system.

\section{Experiment 3}

(1) A and B teams in experiment 2 were regrouped (each team having the same number of participants) to simulate $\mathrm{X}$ and $\mathrm{Y}$ in figure 3 .

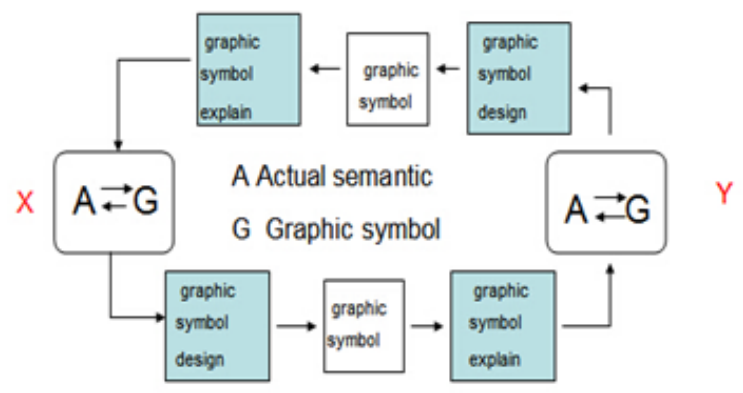

Fig. 3. Communication model using graphical symbols 
(2) Following the simulation process of " $X$ (understanding of reality) $->$ symbol $->Y$ (understanding of reality)", experiment 3 gave the conceptual ideas of several new symbols which had not been used before (to be called the "source semantics"). After that, group $\mathrm{X}$ organized the symbols into communicative sentences in graphs. Then these organized graphs were given to group $\mathrm{Y}$ to translate into sentences (to be called "target semantic"). In each cycle of these experiments, symbols were first distributed to group $\mathrm{X}$ (or Y) to present in graphs. When the graphs were ready, they were given to group $\mathrm{Y}$ (or $\mathrm{X}$ ) to translate.

(3) Recycling semantics "source semantics" and "target semantic" test, carries on the comparison and evaluate the degree of similarity between them.

\section{$4 \quad$ Analyses and Results}

\subsection{Measures}

\section{Experiment 1}

In this paper, fuzzy comprehensive evaluation method (Fang Ke, etc., 2011) conducted a questionnaire survey data processing and analysis.

a. handling method

Establishing factor set and evaluation set. The factors set are expressed as:

$$
\mathrm{U}=\left\{\mathrm{U}_{1}, \mathrm{U}_{2}, \mathrm{U}_{3}, \mathrm{U}_{4}, \mathrm{U}_{5}, \mathrm{U}_{6}\right\}
$$

Which, $\mathrm{U}_{1}$ : can associate, $\mathrm{U}_{2}$ : can be recognized, $\mathrm{U}_{3}$ : meaning clear, $\mathrm{U}_{4}$ : concise design, $\mathrm{U}_{5}$ : attractive, $\mathrm{U}_{6}$ : symbolic.

Evaluation sets vector as follows:

$$
\mathrm{V}=\left\{\mathrm{v}_{1}, \mathrm{v}_{2}, \ldots, \mathrm{v}_{5}\right\}
$$

This experiment evaluation set as shown in table 8 .

Table 8. Credibility evaluation set

\begin{tabular}{llllcc}
\hline evaluation & $\begin{array}{l}\text { very } \\
\text { significant } \mathrm{v}_{1}\end{array}$ & $\begin{array}{l}\text { more } \\
\text { significant } \mathrm{v}_{2}\end{array}$ & $\begin{array}{l}\text { general } \\
\text { significant } \mathrm{v}_{3}\end{array}$ & $\begin{array}{l}\text { generally not } \\
\text { significant } \mathrm{v}_{4}\end{array}$ & $\begin{array}{l}\text { not very } \\
\text { significant } \mathrm{v}_{5}\end{array}$ \\
\hline value & 83 & 72 & 65 & 60 & 20 \\
\hline
\end{tabular}

Calculate fuzzy evaluation matrix. To statistics of the questionnaire survey, establish fuzzy relations from factors set to comment, calculating the membership of each.

For a symbol evaluation factor $U_{i}(i=1,2, . ., 6)$, the evaluation statistic is obtained through the questionnaire $\left(\mathrm{x}_{1}, \mathrm{x}_{2}, \mathrm{x}_{3}, \mathrm{x}_{4}, \mathrm{x}_{5}\right)$, the membership function is defined:

$$
U_{i j}=x_{i} / \sum x_{j}(i=1,2, \ldots, 6 ; j=1,2, \ldots, 5)
$$

Can get fuzzy matrix:

$$
\mathrm{R}=\left[\begin{array}{cccc}
u_{11} & u_{12} & \ldots & u_{15} \\
u_{21} & u_{22} & \ldots & u_{25} \\
\ldots & \ldots & \ldots & \ldots \\
u_{61} & u_{62} & \ldots & u_{65}
\end{array}\right]
$$


Using the method of contrast sort, the factor of factors set and calculates the weight of each factor was sorted. Questionnaire, subjects were asked to sort the 6 evaluation factors on importance, endowed the scores for sorting (i.e. ranked first 6 points, second place five points... ranked sixth 0 points), calculate the total score for each factor $U_{i}$, and thus can get indexes weight vector:

$$
\omega=\left(\omega_{1}, \omega_{2}, \omega_{3}, \omega_{4}, \omega_{5}, \omega_{6}\right)
$$

Among them,

$$
\omega_{\mathrm{i}}=\sum_{j=1}^{6} k_{j i} / \sum_{j=1}^{6} \sum_{i=1}^{6} k_{j i}
$$

$\mathrm{i}=1,2, \ldots, 6, \mathrm{j}=1,2, \ldots, 6$ and $\sum \omega_{\mathrm{i}}=1$.

\section{Experiment 2}

Using sememe analysis (Feng, 2010) score, while scoring hits by analysis of the semanteme of the subjects answer hit on all the proportion of the semanteme[9]. The answer on subjects sememe analysis conducted with the answer set semantics and comparison, hit 1 point, the semantic meaning of the answer appears non-prime minus -1 point (because it wrong), no negative points, the lowest score is 0 point.

\section{Experiment 3}

Using the same "plain meaning analysis" from experiment 2, an analysis was done of the recycled "source semantics" and "target semantic" to identify the similarity and difference of "source semantics" and "target semantics". Below is the equation used for similarity calculation:

$$
\mathrm{W}=[\mathrm{SS} \cap \mathrm{TS}] /[\mathrm{SS} \cap \mathrm{TS}]
$$

Which, $\mathrm{SS}=$ Source Semantic, $\mathrm{TS}=$ Target Semantic.

\subsection{Results}

\section{Experiment 1}

\begin{tabular}{|c|c|c|c|c|c|c|c|c|c|}
\hline \multirow[t]{2}{*}{$\overline{\text { no }}$} & \multirow[t]{2}{*}{ efs } & \multicolumn{6}{|c|}{ Rank Occurrence Statistics $\mathrm{k}_{\mathrm{ij}}$} & \multirow[t]{2}{*}{ tsf } & \multirow{2}{*}{$\begin{array}{c}\text { weight } \\
\omega_{\mathrm{i}}\end{array}$} \\
\hline & & s1 & s2 & s3 & $\mathrm{s} 4$ & s5 & s6 & & \\
\hline 1 & $\mathrm{U}_{1}$ & 8 & 44 & 30 & 2 & 0 & 10 & 404 & 0.205 \\
\hline 2 & $\mathrm{U}_{2}$ & 14 & 22 & 38 & 6 & 0 & 14 & 378 & 0.192 \\
\hline 3 & $\mathrm{U}_{3}$ & 18 & 14 & 10 & 34 & 4 & 14 & 342 & 0.173 \\
\hline 4 & $\mathrm{U}_{4}$ & 28 & 6 & 12 & 30 & 8 & 10 & 362 & 0.184 \\
\hline 5 & $\mathrm{U}_{5}$ & 10 & 6 & 2 & 18 & 34 & 24 & 244 & 0.124 \\
\hline 6 & $\mathrm{U}_{6}$ & 16 & 2 & 0 & 6 & 48 & 22 & 242 & 0.122 \\
\hline
\end{tabular}

The statistics and weight calculation results of questionnaire are shown in table 9.

Table 9. Statistics and weights and calculation result of the questionnaire

Note: no=number, efs=evaluation factors set, $t s f=$ total score of factor, $\mathrm{s} 1=$ section $1, \mathrm{~s} 2=$ section $2, \ldots$ 
Calculate the evaluation results. According to the principle of fuzzy comprehensive evaluation, each symbol fuzzy comprehensive evaluation results can be calculated by the following formula:

$$
\mathrm{f}=\omega \mathrm{RV}^{\mathrm{T}}
$$

Experimental Evaluation of a test groups participate in the survey results of fuzzy symbols shown in Table 10, where I-i represents symbols from 10 randomly selected material 1, II-i represents symbols from 10 randomly selected material 2.

Table 10. Each symbol fuzzy comprehensive evaluation results

\begin{tabular}{ccccccccccccccccccc}
\hline I-1 & I-2 & I-3 & I-4 & I-5 & I-6 & I-7 & I-8 & I-9 & I-10 & V & sd \\
\hline 3033.06 & 3301.63 & 3288.93 & 3351.75 & 3022.67 & 3277.08 & 3166.97 & 3255.63 & 3124.10 & 3091.23 & 3191.3 & \\
\hline II-1 & II-2 & II-3 & II-4 & II-5 & II-6 & II-7 & II-8 & II-9 & II-10 & V & sd \\
\hline 3542.87 & 3546.23 & 3390.23 & 3887.70 & 3509.96 & 3468.34 & 3301.07 & 3586.05 & 3562.79 & 3606.45 & 3560.1 & 92.01 \\
\end{tabular}

Note: $v=$ variance, $s d=$ standard deviation

Table 9 is the sorting result of subjects to male the evaluation factors. Table 10 shows the fuzzy comprehensive evaluation score of material 1 and material 2 samples. Assuming random samples can reflect the characteristics of the whole symbol system, and then you can get the following conclusion: As can be seen from Table 5 weights, subjects generally considered that six Gittins evaluation factors are importance for symbolic design, and the importance is more average. So the evaluation set $\mathrm{U}$ is effective.

Material 1 and material 2 symbol system got the average scores was 3191.31 and 3560.17 , respectively. Therefore, within the scope of the evaluation set $U$, material 2 symbol system is superior to the overall material 1 symbol system, which reflects the desirability of this symbol design method.

Material 1 and material 2 symbol system got the standard deviation was 98.12 and 92.01. The experiment shows that slightly of designed nonverbal graphic symbols are better than the picture of selected from Internet.

\section{Experiment 2}

After scoring and statistical analysis, the experiment 2 obtained the results shown in Table 11, the table shows the cognitive efficiency comparison between two systems.

Table 11. Statistics data of non-verbal symbol systems and common language (such as English) cognitive efficiency comparison test

\begin{tabular}{llcccccc}
\hline \multicolumn{2}{l}{ Cycle experiment } & 1st & 2nd & 3rd & 4th & 5th & 6th \\
\hline Graphic & Accuracy100\% & 60.82 & 70.65 & 78.92 & 82.46 & 86.38 & 86.92 \\
\cline { 2 - 8 } symbol A & st. dev & 0.18224 & 0.17622 & 0.16157 & 0.10225 & 0.07559 & 0.03268 \\
\hline \multirow{2}{*}{$\begin{array}{l}\text { English } \\
\text { language B }\end{array}$} & Accuracy100\% & 30.46 & 42.21 & 52.24 & 60.68 & 72.65 & 78.26 \\
\cline { 2 - 8 } & st. dev & 0.30889 & 0.28323 & 0.20034 & 0.12769 & 0.04643 & 0.03234 \\
\hline
\end{tabular}

Speaking on the overall circumstance, two sets of experimental languages' cognition accuracy improved along with learning time. And the standard deviation of two 
tests' language is decreasing with learning time increasing. This test reflects the subjects were able to improve the ability to master the language and graphic symbols through learning.

Six experiments, material 2 graphic symbols system accuracy was higher than the material 3 in English learning system. The average correct rate of graphical symbols is $77.69 \%$, while the correct rate of English language system is $56.08 \%$. Can be considered after a short learning, the designed symbol has certain efficiency. And after a short learning, English with little effect.

To view the change of accuracy standard deviation from six experiments, except for the last almost standard deviation, the material 2 of standard deviation is lower than the material 3 of standard deviation. This shows that material 2-designed symbol system has good stability in the statistical sense.

\section{Experiment 3}

The similarity data is obtained through analysis and comparison and is shown in Table 12.

Table 12. Similarity Ratio Data

\begin{tabular}{cccccccc}
\hline \multicolumn{2}{c}{ Experiment cycle } & 1st & 2nd & 3rd & 4th & 5th & 6th \\
\hline Graphic & Similarity & 0.6036 & 0.7318 & 0.7032 & 0.7782 & 0.7622 & 0.8375 \\
\cline { 2 - 8 } symbol & St. dev. & 0.2781 & 0.2011 & 0.2983 & 0.2133 & 0.1015 & 0.0621 \\
\hline \multirow{2}{*}{$\begin{array}{c}\text { English } \\
\text { language }\end{array}$} & Similarity & 0.2492 & 0.3274 & 0.4265 & 0.5728 & 0.4872 & 0.6852 \\
\cline { 2 - 9 } & St. dev. & 0.4625 & 0.3010 & 0.2801 & 0.2379 & 0.1583 & 0.0798 \\
\hline
\end{tabular}

Overall, all of the six experiments indicate that the material graphic symbols system is overwhelmingly superior to the material global language of English in terms of "source semantic" and "target semantic", the graphic symbols demonstrate an overall tendency of decreased standard deviation in similarity, superior to that of the global language of English. In this simulated communication experiment, graphic symbols demonstrate a relatively stable high transmission efficiency.

It is also found that the material graphic symbols can reach a similarity standard of $60 \%$ and above after some training. If the training time is increased, this similarity standard will increase and remain stable after reaching as high as $83.7 \%$. This suggests that the symbols used in the experiments are not perfectly designed. For future study, further adjustments and modifications of the rules are needed for the symbols to most effective in communication and exchange.

\section{Discussion and Conclusion}

From the above experiments it can be concluded that:

(1) Relative to the graphic symbols obtained from the Internet, the designed nonverbal graphic symbols are better thus validating hypothesis 1 .

(2) After some brief training, nonverbal graphic symbols designed for this study are proved to be superior in cognitive effect than the English language. This suggests that graphic symbols are easier to acquire than language thus validating hypothesis 2 as well. 
(3) After several rounds of training, simple two-way communication using graphic symbols was achieved hence validating hypothesis 3 too.

In summary, the experiments demonstrate that designed non-verbal graphic symbols are recognizable and can be used for simple communications in the e-commerce context after some training in them.

\section{Further Research}

The experiments designed in this research were rather rudimentary. The content of information to be communicated is obvious. And the designed nonverbal graphic symbols adopted in the experiments are easy to understand too. For future studies, abstract concepts can be incorporated to increase the level of content difficulty and more easy-to-understand rules can be explored to enhance the cognitive effect of nonverbal graphic symbols.

At the same time, efforts should also be made in launching online experiments on the web so that research participants could be expanded to include a more diverse population in Southeast Asian countries.

Acknowledgements. This research was sponsored by the Humanities and Social Sciences General Project (Research on methods of nonverbal symbol instant communication in GMS, grant 11XJA870001) commissioned by China's Ministry of Education.

\section{References}

1. Cheng, F.: A Tentative Study of Nonverbal Communicative Modes in Text-based SCMC. Central China Normal University (2005)

2. Xu, B.: To Book: from point to point. Guangxi Normal University Press (2012)

3. Standing, L.: Learning 10,000 pictures. Quarterly. Quarterly. Journal of Experimental Psychology 25(2), 207-222 (1973)

4. King, L.E.: A laboratory comparison of symbol and word roadway signs. Traffic Engineering and Control 12(10), 518-520 (1971)

5. Walker, R.E., Nicolay, R.C., Stearns, C.R.: Comparative accuracy of recognizing American and international road signs. Journal of Applied Psychology 49(5), 322-375 (1965)

6. Horton, W.K.: The icon book: Visual Symbols for computer Systems and Documentation. John Wiley \& Sons, New York (1994)

7. Likert, R.: A Technique for the Measurement of Attitudes. Archives of Psychology (1), $1-55(1932)$

8. Gittens, D.: Icon-based Human-computer interaction. International Journal of Man Machine Studies 24 (1968, 1986)

9. Feng, Z.: Formal models of natural language processing. University of Science and Technology of China Press (2010) 